\title{
Probabilistic seismic hazard map for Bulgaria as a basis for a new building code
}

\author{
S. D. Simeonova ${ }^{1}$, D. E. Solakov ${ }^{1}$, G. Leydecker ${ }^{2}$, H. Busche ${ }^{2}$, T. Schmitt ${ }^{2}$, and D. Kaiser ${ }^{2}$ \\ ${ }^{1}$ Bulgarian Academy of Sciences, Geophysical Institute, Seismological Department, Sofia, Bulgaria \\ ${ }^{2}$ Institute for Geosciences and Natural Resources, Hannover, Germany
}

Received: 20 July 2006 - Revised: 20 September 2006 - Accepted: 20 September 2006 - Published: 10 October 2006

\begin{abstract}
A seismic hazard map proposed as part of a new building code for Bulgaria is presented here on basis of the recommendations in EUROCODE 8.

Seismic source zones within an area of about $200 \mathrm{~km}$ around Bulgaria were constructed considering seismicity, neotectonic and geological development. The most time consuming work was to establish a homogeneous earthquake catalogue out of different catalogues.

The probabilistic seismic hazard assessment in terms of intensities is performed following Cornell (1968) with the program EQRISK (see McGuire, 1976), modified by us for use of intensities. To cope with the irregular isoseismals of the Vrancea intermediate depth earthquakes a special attenuation factor is introduced (Ardeleanu et al., 2005), using detailed macroseismic maps of three major earthquakes.

The final seismic hazard is the combination of both contributions, of zones with crustal earthquakes and of the Vrancea intermediate depth earthquakes zone. Calculations are done for recurrence periods of 95,475 and 10000 years.
\end{abstract}

\section{Introduction}

Bulgaria, situated in the Balkan Region as a part of the Alpine-Himalayan seismic belt, characterized by high seismicity, is exposed to a high seismic risk. From plate-tectonic point of view, the Balkan Region is an element of the continental margin of Eurasia and is located between the stable part of the European continent to the north and the ophiolitic sutures to the South. South of the sutures, fragments of the passive continental margin of Africa crop out (Boyanov et al., 1989). The neotectonic movements on the Balkan Region are controlled by the extensional collapse of the late Alpine orogen, and are influenced by the extension behind

Correspondence to: G. Leydecker

(guenter.leydecker@bgr.de) the Aegean arc and by the complicated vertical and horizontal movements in the Pannonian region (Zagorchev, 1992).

Over the centuries, Bulgaria has experienced strong earthquakes. In historical aspect, it is worth mentioning the 1818 (VIII-IX MSK) and the 1858 (IX MSK, $M_{S} \approx 6.3$ ) earthquakes near the capital Sofia. Some of Europe's strongest earthquakes in the 20th century occurred on the territory of Bulgaria. At the beginning of the last century (from 1901 to 1928) five earthquakes with magnitude $M_{S} \geq 7.0$ occurred there. Strong seismic activity took place in SW Bulgaria during 1904 to 1906. The seismic sequence started on 4 April 1904 with two catastrophic earthquakes within 23 minutes (the first quake with $M_{S}=7.1$ considered as a foreshock and the second one, the main shock, with $M_{S}=7.8$ and epicentral intensity $I_{\text {epic }}=X$ ). Along the Maritza valley (central part of Bulgaria), a sequence of three destructive earthquakes occurred in 1928. However, such large earthquakes did not occur in Bulgaria since that time. The 1986 earthquake of magnitude $M_{S}=5.7$ in central northern Bulgaria (near the town Strazhitza) is the strongest quake after 1928. Moreover, the seismicity of the neighboring areas, from Greece, Turkey, former Yugoslavia and Romania (especially the Vrancea intermediate depth earthquakes), contribute to the seismic hazard in Bulgaria.

During the last decades, several papers have been published about the seismic hazard in Bulgaria. Bonchev et al. (1982) proposed a seismic zoning of Bulgaria based on an analysis incorporating the seismicity and most of the geological and geophysical data available at that time. Their study resulted in seismic hazard maps for Bulgaria in terms of MSK-1964 intensities for 100, 1000 and 10000 years return periods; the map for 1000 years return period is included in the current building code of Bulgaria. OrozovaStanishkova and Slejko (1994), considering different probabilistic approaches and extremely detailed zonation (that does not seem opportune with the present knowledge of the regional seismotectonics), provide seismic hazard estimates

Published by Copernicus GmbH on behalf of the European Geosciences Union. 
for both intensity and peak ground acceleration (PGA) for 100 years return period. Van Eck and Stoyanov (1996) performed a PSHA for southern Bulgaria. They proposed a zonation model based on the hypothesis that southern Bulgaria and northern Greece can be considered as one seismotectonic unit related to that of the Aegean Sea. Probabilistic seismic hazard estimates for southern Bulgaria in terms of PGA and 0.01 annual probability of exceedance were presented in that study. A probabilistic seismic hazard map in terms of PGA for Sofia area for a 1000 year return period was published by Solakov et al. (2001). Their hazard analysis is based on a simplified seismogenic model, derived from the seismic zoning of Bulgaria.

In all these preceding papers only magnitude-frequency relations are used and the epicentral or site intensities for given distances are estimated using magnitudes. In contrast, in the present paper the intensity-frequency relations and the distance dependent site intensities are computed as a function of observed epicentral intensities (MSK-1964), based on a new homogeneous catalogue for the whole area. Among the papers mentioned above, only Bonchev et al. (1982) have performed hazard analysis for the whole territory of Bulgaria for different probabilities of exceedance, but not for a 475 years return period as recommended in EUROCODE 8 (EC8).

In the present study seismic hazard maps for Bulgaria are presented in terms of macroseismic intensities in agreement with EC8. As recommended in EC8, the maps are calculated for a 475 years return period (probability of exceedance of $10 \%$ in 50 years) and for a 95 years return period (probability of exceedance of $10 \%$ in 10 years). A special feature of our paper is that the irregular macroseismic effects of the Vrancea intermediate depth earthquakes are directly included in the seismic hazard calculations. An appropriate spatial treating of Vrancea intermediate depth earthquakes is of great importance for an adequate hazard assessment, because these earthquakes dominate the hazard of large parts of Northern Bulgaria.

\section{Earthquake catalogue}

The area within a radius of about $200 \mathrm{~km}$ surrounding Bulgaria encompasses the territories of southern Romania, the eastern parts of Albania and former Yugoslavia, the northern parts of Greece, Turkey and Aegean Sea, and the Marmara Sea.

The seismicity for the area bordered by $39^{\circ} \mathrm{N}-49^{\circ} \mathrm{N}$ and $19^{\circ} \mathrm{E}-30^{\circ} \mathrm{E}$ is mainly compiled from the catalogues for Central and Southeastern Europe (Shebalin et al., 1998) and for Greece and surrounding area (Papazachos et al., 2000). The data were checked and complemented with data from the following catalogues:

- Christoskov et al. (1979): Bulgaria, centuries V B.C. XIX AD;
- Grigorova et al. (1979): Bulgaria and adjacent areas, 1900-1977;

- Solakov and Simeonova (1993): Bulgaria, 1981-1990;

- Papazachos et al. (2005): Mediterranean and surrounding area, 1901-2004;

- Kárník (1996): Europe and the Mediterranean, 18001990.

A homogeneous catalogue was obtained by checking and correcting epicentral intensity $I_{\text {epic }}$ (MSK-1964), surfacewave magnitude $M_{S}$, and epicentral coordinates. In the compiled catalogue the size of an earthquake is given in terms of intensity $I_{\text {epic }}$, and of magnitude $M_{S}$ whenever possible.

As a Poisson model for the seismicity is assumed, only independent events should be included in the analyses. The fore- and aftershocks were removed by using a space-time . More specifically, in the case of more than one earthquake within 10 days and $50 \mathrm{~km}$ distance only the strongest event is used for the statistics; the others are considered as statistically dependent and rejected from the catalogue. The earthquake catalogue thus obtained of the considered area consists of nearly 2750 events with epicentral intensity $I_{\text {epic }} \geq 4$. This catalogue was used for all following analyses.

Because the compiled catalogue was going to be used for seismic hazard analyses it was necessary to examine the completeness of the data using Stepp's (1971) test. Stepp's (1971) analysis provides a method for the analytical determination of time intervals in which a particular intensity class (or magnitude) is likely to be completely reported. The test results imply that it is possible to create homogeneous data samples by determining intervals over which earthquakes in different intensity classes are completely reported.

\section{Probabilistic Seismic Hazard Assessment (PSHA)}

We performed a PSHA, using a method which deduces the causative sources, characteristics, and ground motions for future earthquakes (McGuire, 1993). This method was first published by Cornell (1968), with many applications since then. The program EQRISK (McGuire, 1976) is used in the present study with the epicentral intensity instead of the magnitude as the input parameter. The analysis methodology is based on the conception that the seismic hazard at a site is a function of three main components: the space geometry of seismic sources, the characteristics and statistics of their seismicity and the attenuation of intensity. The resultant hazard at a specified site is obtained by integrating the effects of ground motion from earthquakes of different size occurring at different locations within different seismic source regions and with different frequencies of occurrence. 


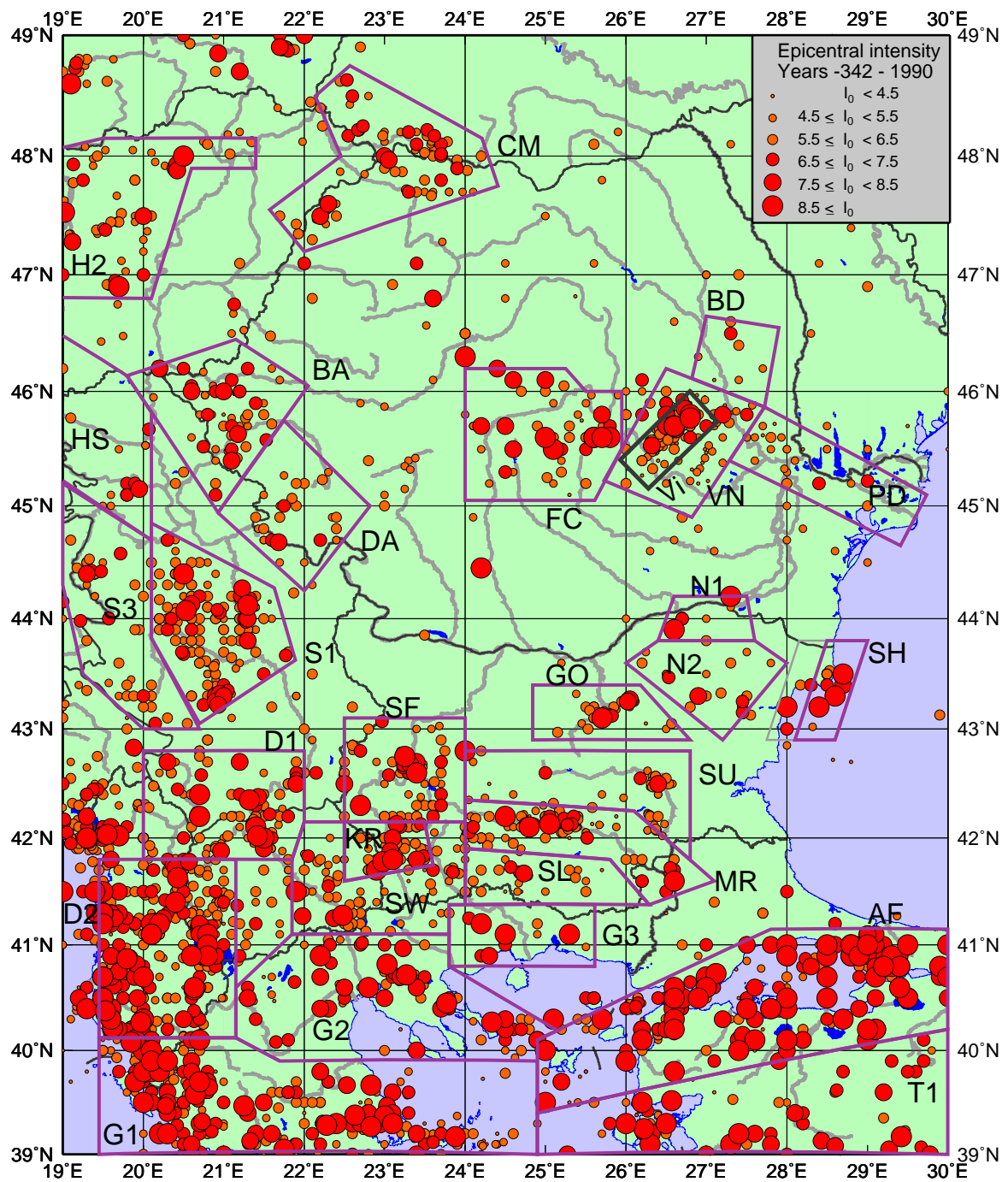

Fig. 1. Epicenter map ( $I_{0}=$ epicentral intensity) with the seismic source zones. Codes of source zones refer to Table 1 .

\subsection{Seismic source zones}

The spatial pattern of seismicity for Bulgaria and surroundings (within a radius of about $200 \mathrm{~km}$ ) is shown in Fig. 1 . The figure shows an epicenter map of the earthquakes with $I_{\text {epic }} \geq 4$ reported in the time $342 \mathrm{BC}-1990 \mathrm{AD}$, together with the seismotectonic zones. Each zone is characterized by its own specific seismicity, and geological and tectonic development. From the seismotectonic analysis of the considered parts of the Balkans this seems more appropriate than to use specific linear fault structures. It is assumed an equal probability that an earthquake occurs in any place within a source zone. The seismic source zones for the territory of Bulgaria are based on Bonchev et al. (1982) and close to those defined by Sokerova et al. (1992) and Dachev et al. (1995). The boundaries of the seismic source zones outside Bulgaria were chosen to reflect the seismicity adequately with respect to the tectonic units and lithosphere structure; in the northern part of the study area they follow the zonation given by Ardeleanu et al. (2005). All earthquakes outside the designed sources are assigned to the "background seismicity". This was not necessary for the Bulgarian territory, because of too low background seismicity. The characteristics of each zone are given in Table 1.

From the analysis of the depth distribution (Sokerova et al., 1992; Dachev et al., 1995) it was recognized that the earthquakes in all zones occurred in the earth's crust $(h<60 \mathrm{~km})$, with the exception of the events in the Vrancea (Romania) intermediate depth zone. The depths distribution shows that the earthquakes in Bulgaria are mainly located in the upper crust, and only a few events are related to the lower crust. The maximum depth is about $50 \mathrm{~km}$ in south-western Bulgaria; outside, the foci affect only the upper $30-35 \mathrm{~km}$. The maximum density of seismicity is found in the layers 
Table 1. Parameters of intensity-frequency relations and input parameters for seismic hazard calculation. The $a$ - and $b$-values are estimated using full intensity values. Half intensity values are added to the next higher intensity class. This enlarges the number of events in each class, which improves the statistical stability and is also more conservative.

\begin{tabular}{|c|c|c|c|c|c|c|c|c|}
\hline Region & code & start & time & $a$ & $b$ & depth & $I_{\max }$ & $I_{\max }$ \\
\hline & & year $^{a)}$ & interval & value & value & $\mathrm{km}$ & observed & credible \\
\hline Anatolian Fault ${ }^{\mathrm{b})}$ & $\mathrm{AF}$ & 1860 & 131 & 3.4915 & -0.2727 & 15 & 10.0 & 10.5 \\
\hline Banat $\mathrm{N}^{\mathrm{c})}$ & BA & 1843 & 148 & 4.0497 & -0.3992 & 10 & 8.5 & 8.5 \\
\hline Birlad ${ }^{\text {d) }}$ & $\mathrm{BD}$ & 1896 & 95 & 3.0802 & -0.4604 & 25 & 6.5 & 7.0 \\
\hline Crisana Marmamures & $\mathrm{CM}$ & 1781 & 210 & 5.1300 & -0.5731 & 10 & 8.0 & 8.5 \\
\hline Dinnaridi 1 & D1 & 1860 & 131 & 4.8226 & -0.4921 & 10 & 9.0 & 9.0 \\
\hline Dinnaridi $2^{\mathrm{e})}$ & D2 & 1860 & 131 & 4.8084 & -0.3943 & 15 & 9.5 & 9.5 \\
\hline Banat $\left.S^{c}\right)$ & DA & 1864 & 127 & 3.5993 & -0.3992 & 12 & 8.0 & 8.5 \\
\hline Fagaras Campulung & $\mathrm{FC}$ & 1517 & 474 & 3.1653 & -0.2711 & 20 & 8.5 & 9.0 \\
\hline Greece 1 & G1 & 1860 & 131 & 4.7075 & -0.3925 & 20 & 10.0 & 10.5 \\
\hline Greece 2 & $\mathrm{G} 2$ & 1860 & 131 & 3.9476 & -0.3692 & 15 & 10.0 & 10.5 \\
\hline Greece 3 & G3 & 1860 & 131 & 2.0740 & -0.2273 & 15 & 10.0 & 10.0 \\
\hline Gorna Orjahovitza ${ }^{\text {f) }}$ & GO & 1860 & 131 & 4.2670 & -0.5000 & 10 & 9.5 & 9.5 \\
\hline Hungary Central & $\mathrm{H} 2$ & 1753 & 238 & 4.4717 & -0.4560 & 10 & 8.5 & 9.0 \\
\hline Hungary + Serbia ${ }^{g}$ ) & HS & 1738 & 253 & 5.1256 & -0.5731 & 8 & 8.5 & 9.0 \\
\hline Kresnah) & $\mathrm{KR}$ & 1860 & 131 & 4.3866 & -0.4831 & 15 & 10.0 & 10.5 \\
\hline Marica & MR & 1860 & 131 & 4.3367 & -0.4688 & 10 & 9.5 & 10.0 \\
\hline NE Bulgaria $1^{\text {i) }}$ & N1 & 1860 & 131 & 2.5296 & -0.3051 & 20 & 9.0 & 9.0 \\
\hline NE Bulgaria $2^{\text {i) }}$ & $\mathrm{N} 2$ & 1860 & 131 & 2.8306 & -0.3051 & 15 & 8.0 & 8.0 \\
\hline Predobroudja ${ }^{\mathrm{d})}$ & PD & 1832 & 159 & 3.5808 & -0.4604 & 20 & 7.5 & 7.5 \\
\hline Serbia E & $\mathrm{S} 1$ & 1886 & 105 & 4.8914 & -0.4866 & 10 & 9.0 & 9.5 \\
\hline Serbia W & S3 & 1894 & 97 & 5.6181 & -0.6990 & 10 & 7.5 & 8.0 \\
\hline Sofia & $\mathrm{SF}$ & 1800 & 191 & 4.3619 & -0.4523 & 10 & 9.0 & 9.5 \\
\hline Shabla ${ }^{\mathrm{j})}$ & SH & 1860 & 131 & 4.3375 & -0.5396 & 20 & 10.0 & 10.5 \\
\hline Southern Bulgaria $2^{\mathrm{k})}$ & SL & 1860 & 131 & 4.2790 & -0.5396 & 10 & 8.5 & 9.0 \\
\hline Southern Bulgaria $1^{\mathrm{k})}$ & SU & 1860 & 131 & 4.3515 & -0.5396 & 10 & 8.5 & 9.0 \\
\hline South-West Bulgaria ${ }^{\mathrm{l})}$ & SW & 1860 & 131 & 5.6658 & -0.6761 & 15 & 10.0 & 10.0 \\
\hline Turkey & $\mathrm{T} 1$ & 1860 & 131 & 4.1423 & -0.3789 & 15 & 10.0 & 10.5 \\
\hline Vrancea, normal depth & $\mathrm{VN}$ & 1802 & 189 & 3.6209 & -0.4515 & 30 & 8.0 & 8.5 \\
\hline Vrancea, intermediate & $\mathrm{Vi}$ & 1701 & 290 & 4.3335 & -0.3971 & 120 & 9.0 & 9.5 \\
\hline Background & $\mathrm{BG}$ & 1817 & 174 & 3.9493 & -0.4530 & 10 & 8.5 & 8.5 \\
\hline
\end{tabular}

a) End year for all regions is 1990; usually, only events with intensities of 5.5 or more are considered.

b) The regression curve in the cumulative intensity-frequency relation for region AF is calculated without the single event with intensity 10.0 MSK for statistical reasons; the next lower class IX contains 9 events.

c) For the two regions BA and DA, the events are added and a common intensity-frequency statistic is done, resulting in a common $b$-value. The a-value is computed using the cumulative number of events with intensity class 7.0 MSK and more for region BA; and with intensity class 6.0 MSK and more for region DA.

d) For the two regions BD and PD, the events are added and a common intensity-frequency statistic is done, resulting in a common $b$-value.

The a-value for each region is computed, using the cumulative number of events with intensity class 5.0 and more.

e) The regression curve in the cumulative intensity-frequency relation for region D2 is calculated without the single event with intensity 10.0 MSK, for statistical reasons; the next lower class IX contains 17 events.

f) The regression curve in the cumulative intensity-frequency relation for region GO is calculated without the single event with intensity 10.0 MSK, for statistical reasons; the next strongest event has intensity 8.0 MSK.

g) Only events with intensities class 7.0 or more are considered.

h) The regression curve in the cumulative intensity-frequency relation for region KR is calculated without the two events with intensity 10.0 MSK, for statistical reasons; the next strongest event has intensity 8.0 MSK.

i) For the two regions $\mathrm{N} 1$ and N2, the events are added and a common intensity-frequency statistic is done, resulting in a common $b$-value. The a-value for each region is computed, using the cumulative number of events with intensity class 6.0 and more.

j) The regression curve in the cumulative intensity-frequency relation for region SH is calculated without the single event with intensity 10.0 MSK, for statistical reasons; then the strongest event has an intensity of 8.0 MSK. The statistic was done for a bigger area (thin lines in Fig. 1) because of suspected mislocated events; the used size of the source region SH is shown by thick lines.

k) For the two regions SL and SU, the events are added and a common intensity-frequency statistic is done, resulting in a common $b$-value. The a-value for each region is computed, using the cumulative number of events with intensity class 6.0 and more.

1) The regression curve in the cumulative intensity-frequency relation for region SW is calculated without the single event with intensity 10.0 MSK, for statistical reasons; the next strongest event has intensity 8.0 MSK. 
between 5 and $25 \mathrm{~km}$. The seismogenic depth of each zone is defined as the depth of maximum seismic energy release and it is given in Table 1 .

The seismicity within the Vrancea (Romania) region consists of two depths horizons: normal depth (less than $60 \mathrm{~km}$ ) and intermediate depth $(60-180 \mathrm{~km})$ earthquakes. Due to extreme irregularities of the isoseismals of intermediate depth earthquakes their effects on seismic hazard have to be treated separately.

\subsection{Earthquake statistics}

We assume a truncated exponential distribution as a seismicity model for each seismic source zone, defined by the parameters $a$ and $b$ of the intensity-frequency relation and by the maximum possible intensity $I_{\max }$ (maximum credible earthquake). The parameters $a$ and $b$ for each seismic source zone were calculated by the least square method using the following equation:

$\log N(I)=a+b I_{\text {epic }}$

where $N(I)$ is the cumulative number of earthquakes with intensity $\geq I_{\text {epic }}$.

The beginning of the time period for statistical purposes is chosen according to assumed completeness of the catalogue for events greater than the lowest intensity values used in statistics ( $a$ and $b$ in Table 1). In parallel, we estimated the completeness using results from Stepp's test that is different for different intensities. The seismic hazard maps we computed with the resulting $a^{\prime}$ - and $b^{\prime}$-values differ only slightly for a recurrence period of 475 years; therefore we did not use these for the following computations.

Some of the seismic zones (as for example seismic sources N1 and N2 in Northern Bulgaria, see Table 1) display low and disperse seismicity. Since it is not possible to determine a reliable intensity-frequency relation for each of these sources separately, they are treated in a special way (see Table 1) to calculate the intensity-frequency statistics.

All model parameters for PSHA are summarized in Table 1 .

\subsection{Attenuation relationship}

In the program EQRISK we implemented the intensity attenuation function of Sponheuer (1960) which is based on Kövesligethy (1907).

$I_{\text {site }}=I_{\text {epic }}-3 \log (r / h)-1.3 \alpha(r-h)$

$I_{\text {epic }}$ is the epicentral intensity, $I_{\text {site }}$ is the intensity at a site at hypocentral distance $r(\mathrm{~km}) ; h$ is the focal depth $(\mathrm{km})$; and $\alpha$ is the absorption coefficient, here $0.002 \mathrm{~km}^{-1}$.

For a hazard curve at a site EQRISK cuts all source regions into finite ring segments with their assigned statistical parameters. Then the site intensities caused by earthquakes

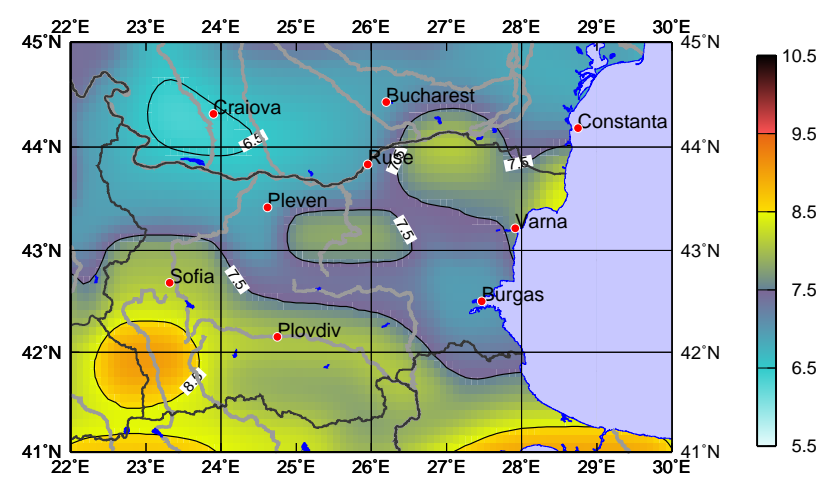

Fig. 2. Seismic hazard from source zones of normal depth for a recurrence period of 475 years; colours represent the intensities in MSK-1964 scale.

of each segment are calculated assuming a standard deviation of half an intensity. The sum of the contributions of all regions finally leads to the annual probability of exceedance at each grid point of the hazard map. These calculations are done for all points between $39^{\circ} \mathrm{N}$ to $48.5^{\circ} \mathrm{N}$ and $20.0^{\circ} \mathrm{E}$ to $30.0^{\circ} \mathrm{E}$ every $0.1^{\circ}$ in latitude and $0.2^{\circ}$ in longitude. Figure 2 shows the seismic hazard for Bulgaria due to the earthquakes of normal depths only, for a recurrence period of 475 years.

\subsection{Treatment of Vrancea intermediate depth zone}

The macroseismic field of intermediate depth earthquakes of the Vrancea zone (Romania) is very irregular. As the attenuation law (Eq. 2) does not consider spatial differences in damping, a new empirical approach is chosen to take the directionality of attenuation and local site effects into account. Therefore a factor $\Omega$ is introduced into Eq. (2) (Ardeleanu et al., 2005):

$I_{\text {site }}=I_{\text {epic }}-3 \log (r / h)-1.3 \alpha \Omega(r-h)$

Using detailed macroseismic maps of three strong Vrancea intermediate depth earthquakes (see Ardeleanu et al., 2005) $\Omega$ is calculated for each observation point. For simplification $\alpha$ is fixed to $0.001 \mathrm{~km}^{-1}$. Strong local variations of $\Omega$ are avoided by calculating mean values inside grid cells of $0.50^{\circ}$ in longitude and $0.25^{\circ}$ in latitude, separately for each event. The median is taken to combine all three grids. Intensities for cells without observations were 2-D-interpolated respectively extrapolated.

Using the corresponding assigned $\Omega$ values, the seismic hazard from the Vrancea Intermediate Depth Zone (Vi) is calculated in the same way as for the crustal zones. A seismogenic depth of $120 \mathrm{~km}$ is assumed for Vi source zone. Figure 3 shows intensities for a recurrence period of 475 years. 


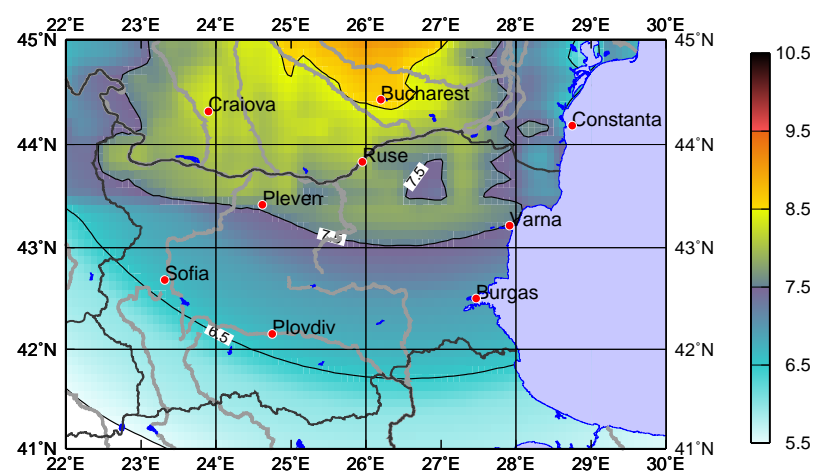

Fig. 3. Seismic hazard from Vrancea events of intermediate depth for a recurrence period of 475 years; colours represent intensities in MSK-1964 scale.

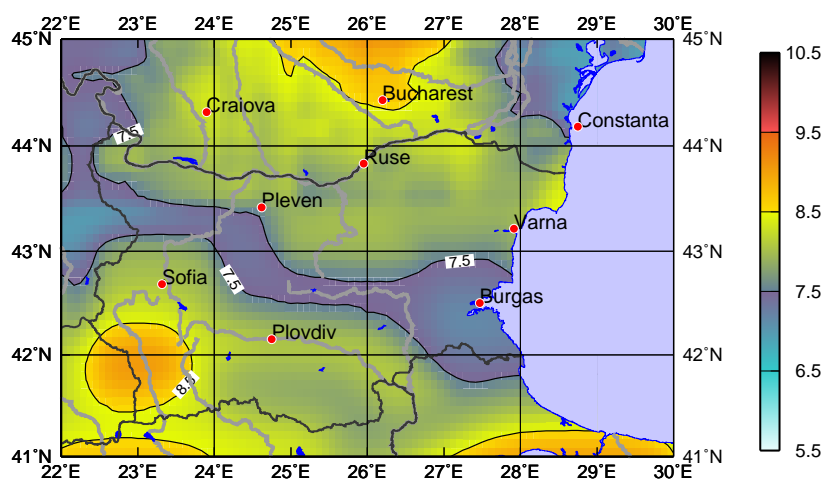

Fig. 4. Seismic hazard from all source zones for a recurrence period of 475 years; colours represent intensities in MSK-1964 scale.

\section{Results}

The final seismic hazard map for a recurrence period of 475 years in Fig. 4 is a combination of the two maps, for normal depth source zones (Fig. 2) and for the Vrancea intermediate depth zone (Fig. 3). The influence of the Vrancea intermediate depth zone on the seismic hazard for Bulgaria is important only to its Northern part. The building code EC 8 recommends a recurrence period of 475 years (probability of exceedance of $10 \%$ in 50 years) for the design earthquake (Fig. 4). Besides, in order to limit the damage of buildings and financial loss in case of weaker earthquakes with higher frequency of occurrence, a second hazard level in EC8 is recommended in addition, corresponding to a recurrence period of 95 years (probability of exceedance of $10 \%$ in 10 years), (Fig. 5).

Special structures like nuclear power plants and large dams are beyond the scope of EC 8, as they require higher safety standards, including longer recurrence periods, e.g. 2475 years (2\% in 50 years) for dams and 10000 to 100000 years for nuclear facilities. Figure 6 shows the seismic hazard for a recurrence period of 10000 years in order to give decision

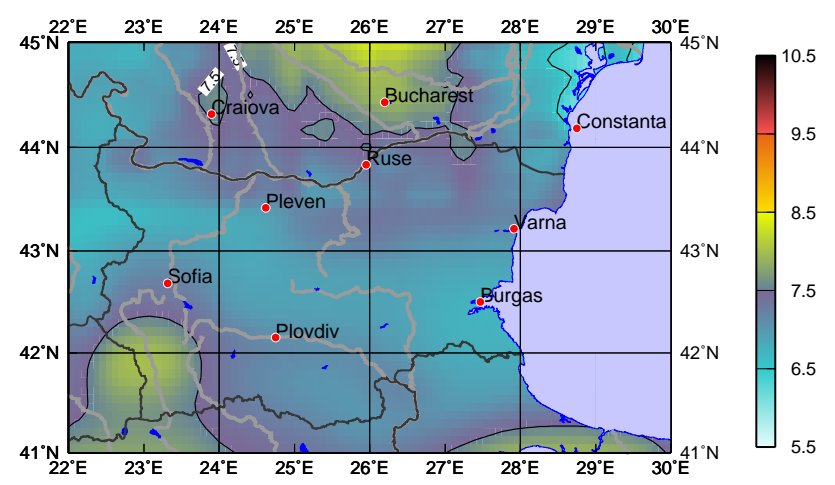

Fig. 5. Seismic hazard from all source zones for a recurrence period of 95 years; colours represent intensities in MSK-1964 scale.

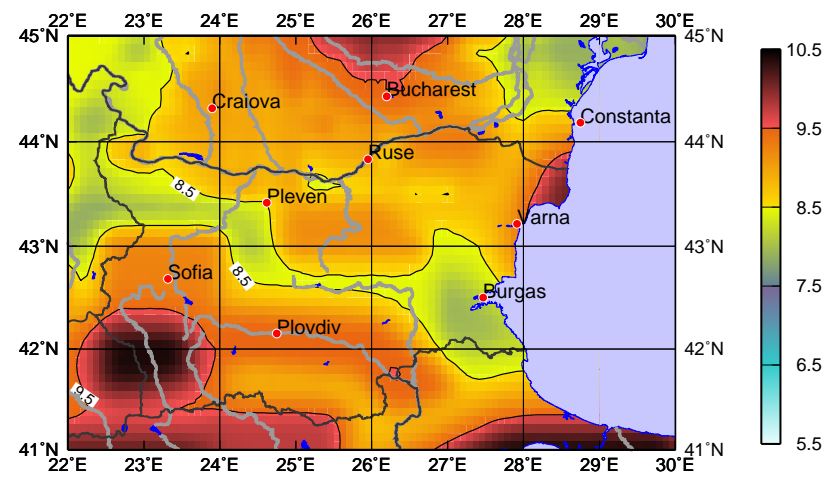

Fig. 6. Seismic hazard from all source zones for a recurrence period of 10000 years; colours represent intensities in MSK-1964 scale.

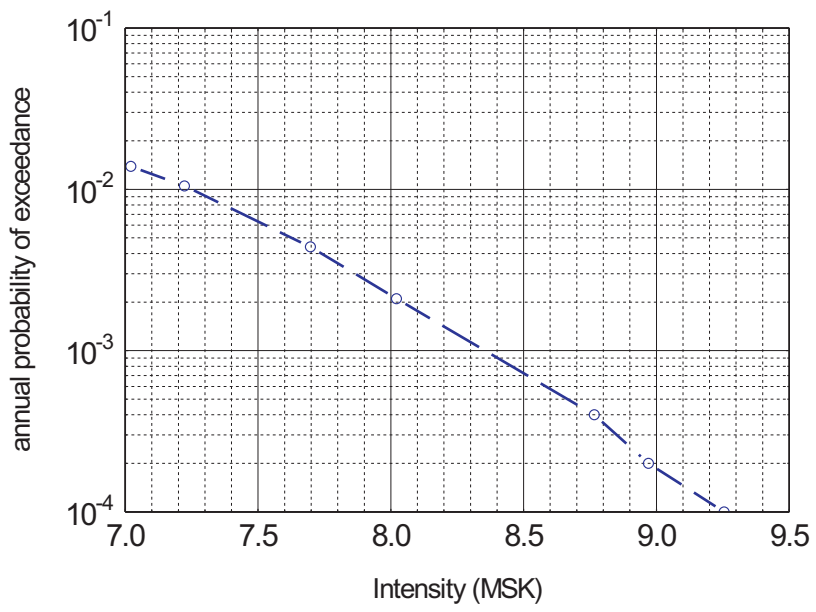

Fig. 7. Seismic hazard curve for Sofia city.

makers first information for regional planning. This map of course can not replace site specific expertises.

A hazard curve for the capital Sofia, extracted from the hazard data set, is presented in Fig. 7. 
Acknowledgements. We are grateful to L. Ardeleanu and K.-P. Bonjer for their critical and constructive review. The stay of S. D. Simeonova and D. E. Solakov in the Federal Institute for Geosciences and Natural Resources, Hannover, Germany, was supported by the German Federal Ministry of Economics and Technology as part of the programme "South East Europe Partnership for Qualification”.

Edited by: P. F. Biagi

Reviewed by: L. A. Ardeleanu and K.-P. Bonjer

\section{References}

Ardeleanu, L., Leydecker, G., Bonjer, K.-P., Busche, H., Kaiser D., and Schmitt, T.: Probabilistic seismic hazard map for Romania as a basis for a new building code, Nat. Hazards Earth Syst. Sci., 5, 679-684, 2005,

http://www.nat-hazards-earth-syst-sci.net/5/679/2005/.

Boyanov, I., Dabovski, Ch., Gocev, P., Harkovska, A., Kostadinov, V., Tzankov, Tz., and Zagorchev, I.: A new view on the Alpine tectonic evolution of Bulgaria, Geol. Rhodopica, 1, 107-122, 1989.

Bonchev, E., Bune, I., Christoskov, L., Karagjuleva, J., Kostadinov, V., Reisner, G., Rizhikova, S., Shebalin, N., Sholpo, V., and Sokerova, D.: A method for compilation of seismic zoning prognostic maps for the territory of Bulgaria, Geol. Balcanica, 12(2), 2-48, 1982.

Christoskov, L., Grigorova, E., Sokerova, D., and Rijikova, S.: New catalogue of the earthquakes in Bulgaria for the period V century BC to XIX century (1899), Archives of the Geophysical. Inst., Bulg. Acad. Sci., (unpublished), 1979 (in Bulgarian).

Cornell, C.: Engineering Seismic Risk Analysis, BSSA, 5, 15831606, 1968.

Dachev, H., Vaptzarov, I., Filipov, L., Solakov, D., Simeonova, S., and Nikolova, S.: Investigations and activities for increasing of the seismic safety of the PNPP Belene site, Geophysical Institute Final Report, (unpublished), p. 250, 1995,

Grigorova, E., Sokerova, D., Christoskov, L., and Rijikova, S.: Catalogue of the earthquakes in Bulgaria for the period 1900-1977, Archives of the Geophysical. Inst., Bulg. Acad. Sci. (unpublished), 1979 (in Bulgarian).

Kárník, V.: Seismicity of Europe and the Mediterranean, Academic publishing house of Czech Republic, 1996.

Kövesligethy von, R.: Seismischer Stärkegrad und Intensität der Beben, Gerlands Beiträge zur Geophysik, Band VIII, Leipzig, 1907.
McGuire, R.: Computations of seismic hazard, Annali di Geofisica, 36(3-4), 181-200, 1993.

McGuire, R.: FORTRAN Computer Program for Seismic Risk Calculations, U.S. Geol. Surv. Open-File Rep. 76-67, p. 90, 1976.

Orozova-Stanishkova, I. and Slejko, D: Seismic Hazard of Bulgaria, Natural Hazards, 9, 247-271, 1994.

Papazachos, B. C., Cominakis, P. E., Karakaisis, G. F., Karakostas, B. G., Papaioannou, Ch. A., Papazachos, C. B., and Skordilis, E. M.: A catalogue of earthquakes in Greece and surrounding area for the period 550 BC-1999, Publ. Geoph. Lab. Univ. of Thessaloniki, 1, 333p, (data file), 2000.

Papazachos, B. C., Cominakis, P. E., Skordilis, E. M., Karakaisis, G. F., and Papazachos, C. B.: A catalogue of earthquakes in the Mediterranean and surrounding area for the period 1901-2004, Publ. Geoph. Lab. Univ. of Thessaloniki (data file), 2005.

Shebalin, N. V., Leydecker G., Mokrushina, N., Tatevossian, R., Erteleva, O., and Vassilev, V.: Earthquake Catalogue for Central and Southeastern Europe, European Commission, Report No. ETNU CT93-0087, Brussels, http://www.bgr.de/quakecat, 1998.

Sokerova, D., Simeonova, S., Nikolova, S., Solakov, D., Botev, E., Glavcheva, R., Dineva, S., Babachkova, B., Velichkova, S., Maslinkova, S., Donkova, K., Rizikova, S., Arsovski, M., Matova, M., Vaptzarov, I., and Filipov, L.: Geomorphology, neotectonic, seismicity and seismotectonic of NPP Kozloduy, Geophysical Institute Final Report (unpublished), p. 200, 1992.

Solakov, D. and Simeonova, S. (Eds.): Bulgaria Catalogue of Earthquakes 1981-1990, Sofia Press, p. 40, 1993.

Solakov, D., Simeonova, S., and Christoskov, L.: Seismic hazard assessment for Sofia area, Annali di Geofisica, 44(3), 541-556, 2001.

Sponheuer, W.: Methoden zur Herdtiefenbestimmung in der Makroseismik. (Methods for depths estimation in macroseismic), Freiberger Forschungs-Hefte C 88, 117 pp., Akademie Verlag Berlin, 1960.

Stepp, J.: An investigation of earthquake risk in the Puget Sound area by use of the type I distribution of large extremes, Ph.D. thesis, Pennsylvania Univ., p. 131, 1971.

van Eck, T. and Stoyanov, T.: Seismotectonics and seismic hazard modeling for Southern Bulgaria, Tectonophysics, 262, 77-100, 1996.

Zagorchev, I.: Neotectonic of the central parts of the Balkan Peninsula: basic features and concepts, Geol. Rundsch., 81(3), 635654, 1992. 